\title{
A Novel Approach of Smart Water Flow Meter using IOT
}

\author{
Madala Kranthi ${ }^{1}$, Velagapudi Sreenivas ${ }^{2}, K$. Prabhakar $^{3}$ and $G$. Ramesh $^{4}$ \\ ${ }^{1}$ Department of Electronics \& Instrumentation Engineering, V.R Siddhartha Engineering College, Kanuru,Vijayawada. \\ ${ }^{2,3}$ Department of Computer Science and Engineering, Dhanekula Institute of Engineering and Technology, Vijayawada. \\ ${ }^{4}$ Associate Professor, Department of Computer Science and Engineering, GRIET, Hyderabad, Telangana India.
}

\begin{abstract}
The point of this paper is on DESIGN OF SMART WATER FLOW METER which has gotten a conspicuous subject inside the present mechanical discourse. During this snappy paced lifestyles water providers and customers need to present any other water system which is steadily gainful and also faster digital water meters are adjusted test the degree of water used by private and commercial enterprise structures which are given water through an untamed office device. Thus via using this we are able to retain seeing at the usage of water by way of diverse clients. The essential target is to shape office logically in a position and direct which lessens the manual help, terminate affirm and time gifted response for the incredible water shape. This snappy paced existence water providers and shoppers wishes to introduce some other water gadget which is regularly successful and nearly snappier. Modernized water meters are adjusted examine the proportion of water used by private and business systems which are given water by way of an untamed water device. On this manner by using this we will continue disapproving of the usage of water via various customers. The fundamental purpose is to form water progressively reliable and direct which diminishes the manual help, take a seat back equipped course of motion for the dumbfounding water structure. Aside from created international locations, the water elements in others gift with a sensor that is labored electronically. Throughout this enterprise a node mcu based charging structure is given. That is frequently a structure which prompts a homogenous trouble free office what's more, charging giving most notable agreement to customers and development in water use survey. Keywords: Electronic Water meter, Node McU, Sensors
\end{abstract}

\section{Introduction}

Water infelicity at some stage in dispersal is visible as a fundamental waste. It's been optically visible that a number of di hydrogen monoxide tribulations happen near the wellspring of cleaned di hydrogen monoxide, even earlier than the scattering kind out. Estimations of consistent with capita di hydrogen monoxide transparency display that India is at the present di hydrogen monoxide focused on; future projections show off that India can also have di hydrogen monoxide lack with the aid of yr 2050. In the course of this situation, spillages in the di hydrogen monoxide scattering structure can large have an impact on the di hydrogen monoxide availability. Di hydrogen monoxide circulation conservation wraps the methodologies, structures and activities to direct clean di hydrogen monoxide as apragmaticuseful resource, to make sure about the di hydrogen monoxide circumstance, and to meet rhythmic motion and future human intrigue. It by the way oversees reliably "gazing" the imperativeness meter studying(s).
This device takes out the same old "paper and pen" and on this manner the goofs related with guide scrutinizing /recording/making plans of the meter statistics. Amr confirmed up on the grounds that essentialness meters grew to become shrewd which works returned to the path of motion of microcontrollers in imperativeness meters. Customized meter studying supple mentally makes the information recording short and jelly mazuma on time and consequently consents to the task of robotization [1].

In one of a kind bits of the planet direct di hydrogen monoxide meters are introduced with the aid of di hydrogen monoxide dating to evaluate the supporters di hydrogen monoxide use. Those di hydrogen monoxide meters are tested on a

month premise by a supported master and furthermore the clients invoice is enrolled centered at the demanded charges as doled out by way of the assessment of di hydrogen monoxide wolfed. Some of the time the patron premises don't seem, via all debts, to be correctly open 
and utilization estimates need to be utilized in heck of the di hydrogen monoxide bill [2] .

That is habitually botched willing as exactness cannot be located. This method for manual facts storing up is likewise costly, paintings centered and starting now and into the foreseeable destiny wasteful. Sharp di hydrogen monoxide structures can fill in as separates to triumph over the insufficiencies of manual metering frameworks. There are faraway sensor structures which might be introduced in an incredibly thoughts blowing diverse family units to acquire conflicting estimations that are spoken to in bona fide time. Di hydrogen monoxide metering is that the path towards assessing di hydrogen monoxide use [3].

\section{Literature Survey}

This version has facilitated and finished far off sensor coordinate surveying utilities, for instance, puissance, di hydrogen monoxide. By means of temperance of impediments of general meter investigating, for example, goofs in searching at, blunder, out of doors situations affecting readings, surrendered work we've executed meter analyzing structure dependent on most recent zigbee progression. This framework performs assignments, for example, taking meter analyzing, dissipating of bills, sending notice, reducing and reconnection of move automatically [4] a changed far flung meter-examining shape depending on gsm is brought in this paper. This paper is imperative to get meter investigating whilst required so meter consistent with customers do not must go to each customer for the devoured information direction of motion and to circle the invoice slips. Microcontroller can be utilized to screen and document the meter readings. If there need to be an occasion of a patron defaulter, no persuading idea to send an man or woman of utility to manner the consumer sodality. Utility can cut off and reconnect the client sodality by using minimized message association (sms).

Luis castalieret. Al (1997) depicts structure and amassing of a mere exertion di hydrogen monoxide flow meter that could examine as much as nine liter/minute, evading direct touch of movement with silicon sensors in techniques of analyzing di hydrogen monoxide circulation fees with the advantage of neural frameworks had withal beenproposed[5]. A system for surveying the movement price of airdi hydrogen monoxide horizontal pipeline with the upside of neural networks was suggested by Shiqiancai and haluktoral(1993). In a cream structure model[6], the kohonen Self orchestrating feature map (ksofm) and the multi-layer re inflicting matrix (mbpn) were performed on this paper to quantify the stream rate of character ranges in the air di hydrogen monoxide stream degree.

A perspicacious stream estimation approach using ultrasonic float metre with stepped forward neural form was proposed by Santhosh kv and bk roy(2010). The aim of these paintings is to tighten the degree of linearity of estimation to one hundred percent of the truth, to make the analysis structure versatile for pipe parcel assortments, liquid thickness, and liquid temperature,and to achieve the various objectives by using a truly perfect synthetic neural community[7] .

Youth Woo Lee et. A far flung digital di hydrogen monoxide metre with low strength for computerized metre reading was developed by $\mathrm{Al}(2008)$ in which they used beguiling starting sensors to find the use of di hydrogen monoxide diploma and that they used zigbee faraway display to transfer the use of dihydrogen monoxide diploma to the passage [8] .

Jadgatabiet javadrezane, Instead of direct assessment of the critical fluid stream, $\mathrm{Al}(2010)$ developed an assistant fluid flow metre in which the production of an accomplice fluid is assessed.The companion fluids were implanted into the fundamental fluid and their velocity could be settled by reviewing their pilgrimage time between stand-aside positions [9].

Wenzhaoet zhang,A liquid differential weight circulation sensor for immediate piping was developed by $\mathrm{Al}(2010)$. A weight parcel between the upstream department pipe and the downstream channel is interpreted in this shape and converted via the dp sensor into a voltage symbol. Assessment of the crucial fluid stream. The companion fluids implanted into the fundamental fluid and with reviewing its peregrinate time between stand-aside positions, its velocity might be settled.

Table1: Types of Flow meters

\begin{tabular}{|c|c|}
\hline PRINCIPLE & TYPES \\
\hline Differential Pressure & $\begin{array}{c}\text { Orfice Plate type of meter, } \\
\text { Rotameter, Flow nozzle, } \\
\text { Pitot tube, Venturi Tube }\end{array}$ \\
\hline Positive Displacement & $\begin{array}{c}\text { Rotary Vane type, Disc type, } \\
\text { Reciprocating Piston, Oval } \\
\text { Gear type }\end{array}$ \\
\hline Velocity & $\begin{array}{c}\text { Turbine type, Ultrasonic Doppler } \\
\text { type, Ultrasonic Transit time type, } \\
\text { Vortex Shedding Electro-magnetic }\end{array}$ \\
\hline Mass & Thermal, Coriolis \\
\hline Open Channel & Flume, Weir \\
\hline
\end{tabular}

Zhang wenzhaoet. Al (2010) had advanced a liquid differential weight circulation sensor for immediately pipe. On this shape a weight parcel between the upstream department pipe and the downstream channel is perceived and changed over into a voltage sign through the dp sensor.this voltage sign is transmitted to a chip to choose liquid movement fee [10]. In [11-16] authors have been proposed image transformation and classification techniques used to classify data which is collected from various sensors and also provided details about real time datasets generated from devices. 
Thwe mu han, ohn mar myaing (2011) creates microcontroller-predicated di hydrogen monoxide go with the flow control system. In this structure, as perceiving unit, photo interrupter and opened plate realize approximately brief beat educate for reiterate duty of the microcontroller. This sign is modified over into movement charge by way of programming software [17] .

\section{Theoretical Analysis}

A circulation meter (or circulate sensor) is an device used to check brief, nonlinear, mass or volumetric movement pace of a liquid or a gas. While picking flowmeters, one need to bear in mind such insignificant portions shared feature of plant staff, their relationship in approach and upkeep, keep elements straightforwardness, and period between bafflement history, and so forth, on the precise plant website.

It's also counseled that the cost of the established order be picked on a essential level in the wake of creating those techniques. One of the maximum by using and large watched circulate estimation wrecks is the inversion of this contraption considering the fact that it is coherently slight.

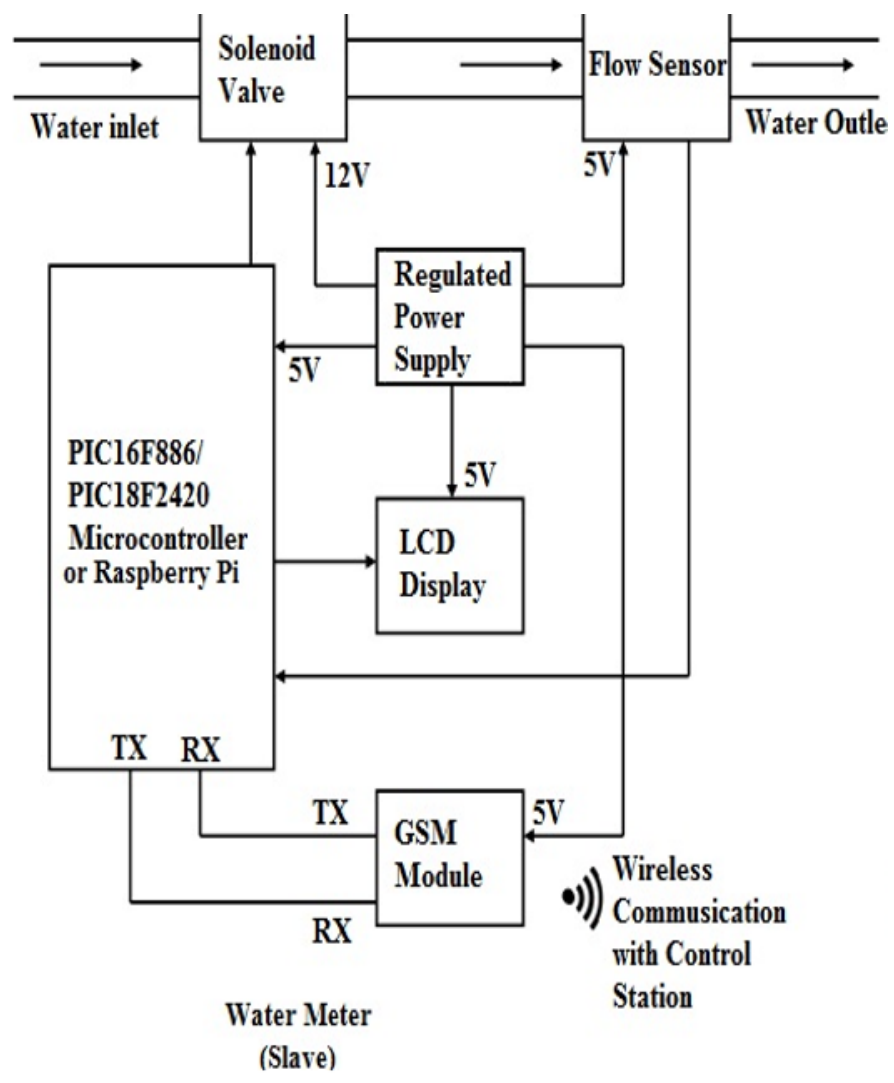

Fig. 1: Block Diagram of a smart water Flow meter
Those "right down to earth" buys may be the most over the pinnacle institutions [18].

This web page will assist you with improving distance move meters, anyhow you may other than address

our software engineers at something point at the off danger that you have any of a kind flow estimation challenges. There are more than one water move meter advances to dissect subordinate upon the water estimation application, upkeep requirements, and budgetary phrases. Such water circulate meters has an outstanding popular of development, unequivocal utility immaculate conditions [19].

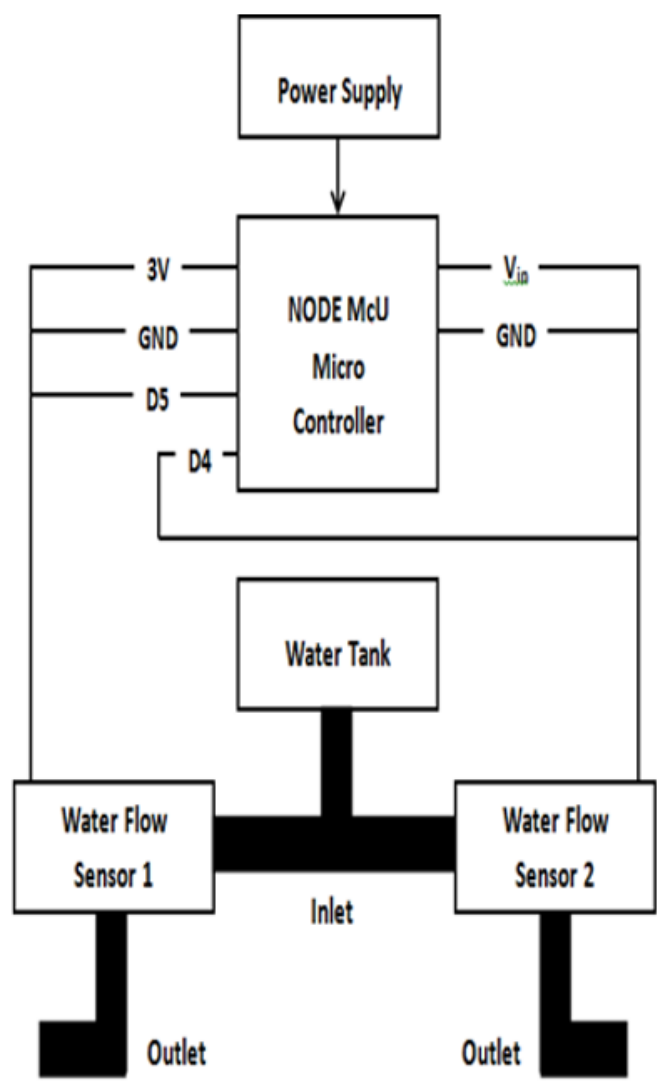

Fig. 2: Flow chart of the system

\section{Methodology}

A stream meter (or circulation sensor) is an instrument used to check active, nonlinear, mass or volumetric circulate pace of a fluid or a gasoline. While choosing circulate meters, one need to don't forget such unnecessary sections shared property of plant personnel, their courting in technique and renovation, keep elements 
receptiveness, and length between sadness history, and so on., on the precise plant website. It's far moreover recommended that the rate of the established order be taken on a widespread experience in the wake of creating these strategies. One of the most by and large watched movement estimation wrecks is the inversion of this sportplan: as opposed to picking a sensor on the way to perform fittingly [20], an undertaking is made to legitimize using a device for the reason that it's miles powerfully mild. The ones "reasonable" buys may be the maximum over the top institutions. This page will help you with making improvements to handle movement meters, at any fee you may likewise address our application engineers at whatever factor in the event which you have any of a kind flow estimation challenges[21].As per the figure 2, there are multiple water circulation meter advances to take a gander at subordinate upon the water estimation utility, renovation requirements, and budgetary terms. Such water movement meters has aphenomenal preferred of development, unequivocal application fantastic situations, and all round price-of- proprietorship [22].

\section{Results}

The table 2 data perusing of water move price with various duplication factors with and without sensor. As in table 2 with the expansion in growth factor the readings regarded with the aid of the sensor debase whilst contrasted with authentic readings and a factor comes where it seems to be near the actual really worth that is the rate at which the water truly streams as expected without the sensor [23].

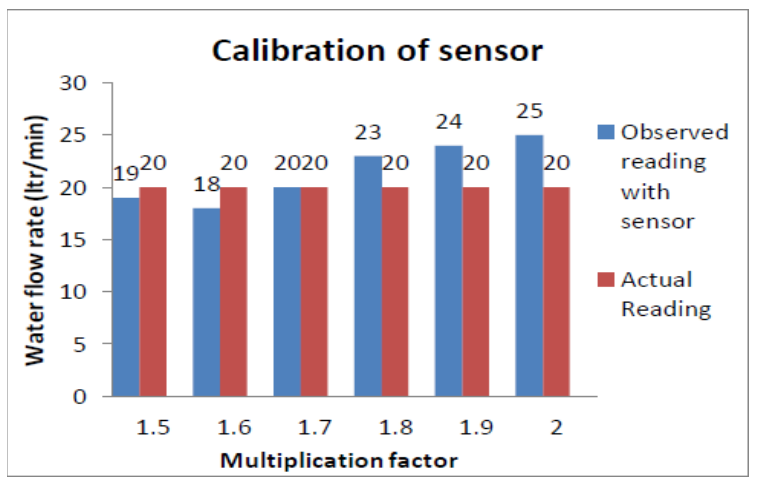

Fig. 3: Calibration of water flow rate with sensor

Figure 3 shows the chart of alignment of sensor which demonstrates that the real perusing we have seen with our sensor is a tad veers off from unique because of air present. Readings are excited about one-of-a-kind volume of water. It's far located that the readings all for our system are approximately identical to the actual readings. As we can see that during table 3 and the graph figure 4 .

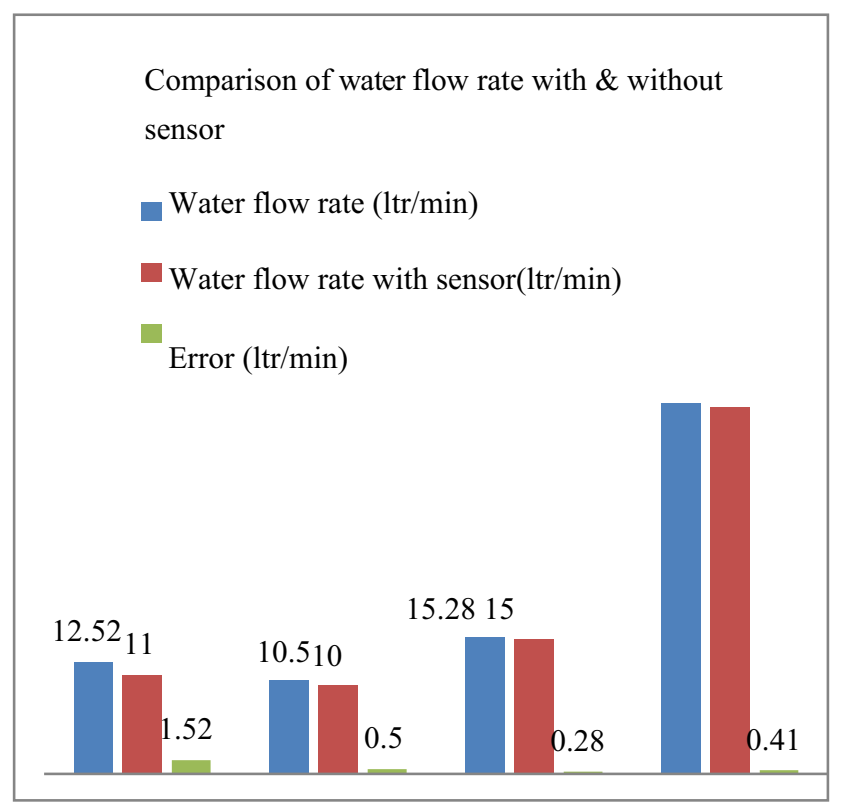

Fig. 4: Comparison between standard and experimental analysis

Table 2: Comparison between standard and experimental analysis

\begin{tabular}{|c|c|c|}
\hline $\begin{array}{c}\text { Water Flow Rate } \\
\text { (Itr/min) }\end{array}$ & $\begin{array}{c}\text { Water Flow Rate } \\
\text { with Sensor } \\
\text { (Itr/min) }\end{array}$ & $\begin{array}{c}\text { Error } \\
\text { (Itr/min) }\end{array}$ \\
\hline 12.52 & 11 & 1.52 \\
\hline 10.50 & 10 & 0.50 \\
\hline 15.28 & 15 & 0.28 \\
\hline 41.40 & 41 & 0.41 \\
\hline
\end{tabular}

\section{Conclusion}

In view of evaluation and shape, the device offers a notable water meter with eco-obliging and essentialness worthwhile machine. Because the incredible water meters are digitized and automatic, high exactness is stored up through decreasing human undertakings. Water theft may be avoided since there are not any mechanical parts that can be supplied to regulate. A circulate sensor based water metering structure was used for robotized charging, abstaining from the impediments of normal water metering systems.

Further, various houses in a shape should use separate stop center points with a not unusual section interfacing with the net for definite charging considering singular use of homes. An assessment of water usage thru diverse stores in a residence became given in order to show occupants on cleaving down wasteful use. This paper suggests the efficient use of an electronic method to control display screen water gracefully and utilization on a progressing premise. 


\section{REFERENCES}

1. Anjana S1, Sahana M N2, Ankhit. K Nataranjan4,K R Shobha5, "An IOT based 6Lo WPAN enabled experiment for water management", IEEE ANTS, (2015).

2. Peter MWANGI, Elijah MWANGI, Patrick M Karimi "A low cost water meter System based on the Global System for Mobile communication". International Journal of computer application.(09758887) volume 142-No.12, (2016).

3. Rob, $\mathrm{K}$ and Gabor , $\mathrm{M}$ (2010). A perspective on radio frequency exposure associated with Residential Automatic meter reading Technology. California, USA Electrical power research InstituteCalifornia.

4. N.R Kolhare, P.R Thorat "An Approach of Flow Measurement In Solar Water Heater Using Turbine Flow Meter", International Journal of Engineering Research \& Technology (IJERT), Vol. 2, (2013).

5. Luis Castaiier, Vicente Jimenez, Manuel Dom'nguez, FrancescMasana and Angel Rodriguez, "Design and fabrication of a low cost water flow meter", IEEE International Conference on Solid-State Sensors and Actuators, Vol. 5, pp. 159-162., (1997).

6. ShiqianCai and HalukToral, (1993) "Flowrate Measurement in Air-Water Horizontal Pipeline by Neural Networks", International Joint Conference on Neural Networks,pp.2013-2016, (1993).

7. Santhosh KV and BK Roy, "An Intelligent Flow Measurement Technique using Ultrasonic Flow Meter with Optimized Neural Network", International Journal of Control and Automation, Vol. 5, pp. 185-196, (2012).

8. Young-Woo Lee, SeongbaeEun, Seung-Hyueb Oh,(2008) "Wireless Digital Water Meter with Low Power Consumption for Automatic Meter Reading", International Conference on Convergence and Hybrid Information Technology IEEE, pp. 639-645, (2008). DOI 10.1109/ICHIT.19/2008.172.

9. JavadRezanejadGatabi, FarshidForouzbakhsh, HadiEbrahimiDarkhaneh, Zahra RezanejadGatabi, MajidJanipour, ImanRezanejadGatabi, "Auxillary Fluid Flow Meter", European Journal of Scientific Research, Vol. 42 , pp.84-92, (2010).

10. Zhang Wenzhao, Liu Zhizhuang, Xu Xiao, Liu Ailing, Chen Aiwu,(2010), "A Liquid DP Flow Sensor on Straight Pipe", International Conference on Industrial Mechatronics and Automation, Vol. 1, pp. 481-485, (2010).

11. Kora, P., Kalva, S.R., Hybrid Bacterial Foraging and Particle Swarm Optimization for detecting Bundle Branch Block, SpringerPlus, 4 (1), art. no. 481, 19 p., (2015).

12. Prasanna Lakshmi, K., Reddy, C.R.K. A survey on different trends in Data Streams, ICNIT 2010 - 2010 International Conference on Networking and Information Technology, art. no. 5508473, pp. 451-
$455,(2010)$.

13. Swaraja K, Medical image region based watermarking for secured telemedicine, Multimedia Tools and Applications, 77 (21), pp. 28249-28280, (2018).

14. Kumar, S.K., Reddy, P.D.K., Ramesh, G., Maddumala, V.R. Image transformation technique using steganography methods using LWT technique, Traitement du Signal, 36 (3), pp. 233-237, (2019).

15. Dhanalaxmi, B., Apparao Naidu, G., Anuradha, K., Adaptive PSO based association rule mining technique for software defect classification using ANN, Procedia Computer Science, 46, pp. 432-442, (2015).

16. Sankara B Babu, A Suneetha, G Charles Babu, Y Jeevan Nagendra Kumar, G Karuna, Medical disease prediction using grey wolf optimization and auto encoder based recurrent neural network, Periodicals of Engineering and Natural Sciences (PEN), (2018).

17. Thwe $\mathrm{Mu}$ Han, OhnMar Myaing, "Design and Construction of Microcontroller-Based Water Flow Control System", International Conference on Circuits, System and Simulation, Vol. 7, pp.304-309.

18. Gang-Li Qiao-Zhen Feng Dong, "Study on wide range turbine flow meter", Proceedings of theFifthInternational Conference on Machine Learning and Cybernetics IEEE, pp. 775- 778, (2006).

19. Enggcyclopedia,"Turbine Flow meters" Available:http://www.enggcyclopedia.com/2012/01/t urbineflow-meters/

20. AKM semiconductors, "HallEffect sensor applicationguide"pp11. Available: http:// ww.akm.com/Brochures/HallSensortechnicalguide .pdf KranthiMadala, NarendraBabuTatini, "IOT Based Agriculture - Field Monitoring and Irrigation Automation System", International Journal of Recent trends in Engineering \& Technology (IJRET), Volume-7,Issue-5, (2019).

21. RiaSood, ManjitKaur, HemantLenka, Academic and Consultancy Services-Division Centre for Development of Advanced Computing(C-DAC), Mohali, India "Design And Development Of Automatic Water Flow Meter" in International Journal of Computer Science, Engineering and Applications (IJCSEA) Vol.3, No.3, (2013).

22. KarstenTawackoliana, JankeesHogendoornb, ThomasLederera, "Calibration of an ultrasonic flow meter for hot water" in Flow Measurement and Instrumentation, Volume 30, Pages166-173,(2013).

23. F. Heitmann, M. Juling, J. Steinbock, PhysikalischTechnischeBundesanstalt, Abbestrae, "Performance of the LDA Volumetric Flow Rate Standard Under Severely Disturbed Flow Conditions" in Flow Measurement and Instrumentation, Volume 74 , Pages 101756, (2020). 